\section{UNG (Uracil-DNA-Glycosidase)}

\section{J. Arnemann}

Abteilung Molekulargenetik, Labor Dr. Wisplinghoff, Köln, Deutschland

\section{Synonym(e) Uracil-DNA Glykosidase}

Englischer Begriff UNG; uracil DNA glycosylase

Definition Das Enzym Uracil-DNA-Glykosidase (UNG), ein Bestandteil des Basenexzisionsreparatursystems (BER), kann vor der PCR-Reaktion gezielt zur Entfernung möglicher Kreuzkontaminationen mit bereits vorhandenen DNAFragmenten eingesetzt werden.

Beschreibung Es gibt mehrere Typen von Glykosidasen, die jeweils spezifisch definierte Basen durch Spaltung der glykosidischen Bindung zwischen der eigentlichen Base und dem Zucker-Phosphat-Rest herausschneiden, am Beispiel des UNG-Enzyms ist es die Base Uracil.

Bei routinemäßigem Einsatz zwecks Dekontamination wird der allgemeine PCR-Reaktionsansatz dahingehend modifiziert, dass neben einer HotStart-DNA-Polymerase (ohne Proofreading-Aktivität) dUTP statt dTTP oder auch als dUTP/dTTP-Mix bei der Amplifikation eingesetzt wird.
Dabei wird dUTP mit vergleichbarer Effizienz wie dTTP in das PCR-Fragment eingebaut.

Insbesondere in der Erregerdiagnostik, wie z. B. HCVDiagnostik, muss sichergestellt sein, dass die z. T. geringen Nachweisraten auch vom untersuchten Patienten und nicht von einer Kreuzkontamination aus vorherigen Ansätzen stammen. Aus diesem Grund wird der PCR-Reaktion das Enzym UNG zugesetzt und das PCR-Reaktionsgemisch anfangs zunächst für 2 Minuten bei $50{ }^{\circ} \mathrm{C}$ inkubiert, um bei möglicherweise kontaminierten DNA-Fragmenten aus einem früheren PCR-Ansatz (sog. Carry-over-Kontamination) die Uracilbausteine herauszuschneiden. Die eigentliche PCRAmplifikation wird anschließend als HotStart-Schritt von 10-15 Minuten bei $95{ }^{\circ} \mathrm{C}$ gestartet, wobei das UNG-Enzym irreversibel inaktiviert und der Zucker-Phosphat-Rest der kontaminierten DNA abgebaut wird. Die potenziell kontaminierten DNA-Fragmente sind hierdurch fragmentiert und können nicht amplifiziert werden, während die eigentliche Patienten-DNA unbehandelt und stabil ist und so selektiv amplifiziert wird. Das Fehlen einer Proofreading-Aktivität der eingesetzten HotStart-DNA-Polymerase verhindert zusätzlich eine mögliche Reparatur der herausgelösten dUTPs.

\section{Literatur}

Tetzner R (2009) Prevention of PCR cross-contamination by UNG treatment of bisulfite-treated DNA. Methods Mol Biol 507:357-370 